\title{
The Foundation and Principles of Critical Thinking
}

\author{
Muhammad Mumtaz Ali
}

\begin{abstract}
This article explains the currently dominant paradigm of critical thinking, which is considered universally applicable, in terms of applying various skills, techniques, standards, and procedures. However, it also contends that emphasizing the technical aspects does not make it critical thinking, for that depends mainly upon its own metaphysics - a view that is never discussed. I contend that the metaphysical premise is more important than the skills and techniques, as it is intimately related to the technical dimensions of critical thinking. I argue that without a true and realistic metaphysical foundation, critical thinking cannot produce good results.
\end{abstract}

\section{Introduction}

The majority of scholars and authors on critical thinking agree that we need to think critically and understand things intelligently and wisely through the applications of techniques and skills. ${ }^{1}$ However, this view is limited and overlooks critical thinking's fundamental metaphysical foundation and underlying integral principles. As critical thinking differs from thinking, it follows a specific framework and works within its own paradigm. I, therefore, contend that our present understanding of it is problematic and lacks a few important aspects that make thinking "critical" in real sense, such as any discussion of its framework, paradigm, and principles. Hence, I argue that we must begin by analyzing these missing aspects, all of which must be true, realistic, authentic, and universal, for this is the only way to develop a truly accurate view of critical thinking.

$\overline{\text { Muhammad Mumtaz Ali is a professor in the Department of Usuluddin and Comparative Re- }}$ ligion, Kulliyyah of Islamic Revealed Knowledge and Human Sciences, Gombak Campus, International Islamic University Malaysia, Kuala Lumpur, Malaysia. 
Given that this understanding requires true, authentic, and universal knowledge, which speculative philosophy and rationalist metaphysics cannot provide, ${ }^{2}$ I analyze existing notions of critical thinking and their metaphysical premises, as well as the framework, paradigm, and certain fundamental principles that transform thinking into critical thinking.

\section{Framework}

Few people are able to think critically and understand things in that light. One way to acquire this skill is to formulate an authentic foundation of a framework and a paradigm of life and the world. Even though we work within the boundary of some metaphysical framework and paradigm, ${ }^{3}$ I contend that each person's knowledge of these must be true and authentic. But how can we be sure of this? For example, I believe that we largely think and act based upon noncritical thinking, especially as regards the metaphysical foundation and principles of critical thinking. ${ }^{4}$

We generally assume that the dominant metaphysical framework and paradigm are realistic, and therefore do not view them from a critical viewpoint. These are based on speculation, conjecture, imagination, and assumption because relativism, which undergirds the Enlightenment, rejects the idea of true, authentic, and universal knowledge. Therefore we cannot use such knowledge to understand life and the world or to erect a structure of thinking and critical thinking. To overcome this failure, we need to acquire accurate knowledge by reexamining and reevaluating our existing perceptions of critical, analytical, and scientific thinking. The first step in this regard is to recognize that we currently do not really understand life, the world, and critical thinking. ${ }^{5}$

\section{The Metaphysical Foundation of Critical Thinking}

If we are to develop any kind of critical thinking, correct knowledge about the truth and reality of life and the world is a prerequisite, the actual foundation and principles of critical thinking. Contemporary literature on critical thinking shows that our knowledge in this regard is erroneous. ${ }^{6}$ In reality, it has ignored this fundamental question, ${ }^{7}$ as have other branches of knowledge. For example, although Socrates asked, "What ought one to do to make life a good life?" he ignored the more fundamental questions of ethics: What is life? What is the origin of life? Who gives and takes life? What is the purpose of life?

The existing literature on ethics does not contain these questions and their answers. ${ }^{8}$ It seems they were not worthy of an answer, especially in the discourse on ethics; however, both ethics and rationality demand that we should 
know them based upon a critical ethical inquiry. Whatever philosophical thought exists today in terms of metaphysical issues was always answered based upon reason and experience. Philosophers sought answers based upon reason and sense perception, not realizing that our faculties can only supply answers based upon conjecture and speculation. Thus, we need to look beyond the current paradigm and admit that our cognitive faculties ${ }^{9}$ are unable to produce facts in the metaphysical domain.

To really understand our faculties, we need to see the truth and reality with new lenses, to see familiar things in alternative ways. This effort demands that we find a way to reexamine the existing paradigms and premises of thinking and critical thinking, drop the false notions associated with them, ${ }^{10}$ and formulate a realistic understanding of critical thinking as regards truth and the reality of this life and the world, along with all that is connected with it.

As this particular understanding is based upon certainty and authenticity, we need genuine knowledge, defined as that which constitutes the genuine foundation and characteristics of critical thinking. History is characterized by two trends: (1) true, authentic, and universal knowledge and (2) conjecture and speculation. ${ }^{11}$ The first one may be called critical thinking, and the second one as merely thinking. In my view, all thought not guided by true, authentic, and universal knowledge is uncertain and therefore inauthentic. In fact, this is one of the fundamental obstacles to developing truth-based and reality oriented thinking and critical thinking. ${ }^{12}$

The current dominant paradigm exists due to the lack of true and authentic thinking and critical thinking. ${ }^{13}$ I posit that a deeper analysis of the metaphysics reveals that current understanding also lacks any rational argument and historical and empirical evidence. To correct this error requires the acquisition of true, authentic, and universal knowledge; however, the so-called Enlightenment replaced such knowledge ${ }^{14}$ with thought and understanding based upon conjecture and speculation. ${ }^{15}$ As a result, we no longer correctly understand such things as ethics, science, scientific thinking, critical thinking, analytical thinking, and creative thinking. For example, ethics was confined to morals and science to the world of nature, ${ }^{16}$ both of which undermine them as disciplines. One wonders why these rational and empirical inquiries were confined to the study of these two specific areas or subject matters. I argue that these methods of inquiry were not applied to metaphysical and spiritual issues because true, authentic, and universal knowledge was rejected.

Clearly, we need this rejected knowledge in order to understand this world. Our dependence upon reason and sense perception continues to move 
us toward an uncertain understanding of the truth and reality of life and the world because all of our discussions and debates are based upon an uncertain foundation.

\section{What Is Needed Today}

Contemporary literature presents critical thinking as being no more than applying skills, techniques, procedures, and processes to examine and evaluate whatever is in this world (e.g., fundamental principles of inductive and deductive logic, reasoning, and methods of proof). ${ }^{17}$ Hence, we build our understanding of critical thinking and explaining its various aspects according to this basic premise and elaborate its importance and characteristics (e.g., examination, analysis, sound argument, evidence, clarity, accuracy, precision, relevance, depth, significance, logic, fairness, and well-reasoned conclusions). We write and talk about it, yet we remain within and therefore do not criticize this underlying premise. In fact, we have accepted it and never stray beyond the accepted framework, even though the foundation and approach of the existing idea of critical thinking are neither holistic nor comprehensive.

Here, we need to understand the difference between thinking and critical thinking. In most cases, we found that the discussion is on thinking, not critical thinking. We fail to understand that critical thinking involves reexamination and reevaluation, whereas thinking is not necessarily based upon critical examination and evaluation. Without the solid foundation and sound criteria detailed above, "critical thinking" is actually no more than "thinking." Most textbooks do not clarify this issue. ${ }^{18}$

\section{The Truth and Reality of True, Authentic, and Universal Knowledge}

While researching this article, I collected data from the Qur'an and determined that it speaks of the existence and availability of this knowledge in terms of revealed knowledge or revelation and presents a powerful ethical discourse along with historical and empirical evidence. An analysis and examination of its claims sheds light on one of its discourse's internal facts: It asks people to consider its ethical discourse, rational arguments, and the provided historical and empirical evidence and then deduce whether it contains the true, authentic, and universal knowledge or not.

Many people generally perceive the Qur'an as the source of religious knowledge; however, its discourse does contain some important dimensions 
that deserve our attention. First, it indisputably offers a model of critical thinking. For example, consider the following verses:

When they are told: "Do not spread mischief on Earth," they ask: "Why? We indeed are the ones who set things right." They are surely the ones who make mischief, but they do not realize it. When they are told: "Believe as others believe," they ask: "Shall we believe as the fools have believed?" Indeed, it is they who are the fools, but they are not aware of it. (Q. 2:11-13) $)^{19}$

Second, we are told to speak about anything related to the metaphysical world based upon accurate knowledge: "Does he have any knowledge of the world beyond the ken of sense perception, and therefore, clearly sees [the Truth]?" (Q. 53:33) and "Many indeed say misleading things without knowledge, driven merely by their desires (Q. 6:119)." ${ }^{20}$ [Emphasis added]

Third, we need knowledge of the metaphysical world, which the Qur'an claims to provide via clear signs. Rejecting these signs based on rationality, historicity, and empiricism seems to be difficult, for they are supported by just such evidence. Hence, the Qur' an asserts that the principle and method of critical thinking is to follow, as a prerequisite, the knowledge revealed by God, the Creator. As the creation of God is not a human activity, as understood in modern philosophy, God's existence is by itself a truth and a reality.

God, the Ever-Living, the Self-Subsisting by Whom all subsist, there is no Creator but He. Neither slumber seizes Him, nor sleep; to Him belongs all that is in the heavens and all that is in the earth ... He knows what lies before them and what is hidden from them, whereas they cannot attain to anything of His knowledge save what He wills them to attain, ... He is All-High, AllGlorious. (Q. 2:255)

In addition, "God is All-Powerful as well as All-Wise" (Q. 2:220) and "God has full knowledge of everything” (Q. 2:231).

As the Creator of everything, God knows what His creatures need.

We said: "Get you down from here, all of you, and guidance [knowledge] shall come to you from Me: then, whoever will follow My guidance need have no fear, nor shall they grieve." (Q. 2:38)

Surely We have brought them a Book which we expounded with knowledge [true, authentic, and universal]; guidance and a mercy to those who believe [understand and accept]. (Q. 7:52 $)^{21}$

Such verses seem to be enough to establish that this kind of knowledge exists.

Fourth, it asserts that speculation and conjecture cannot produce any conclusive knowledge, especially about the metaphysical world: "Most of them 
only follow conjecture; and surely conjecture can be no substitute for truth, God is well aware of whatever they do" (Q. 10:36) and "While they have no knowledge thereof. They only follow their conjecture, and verily, conjecture is no substitute for the Truth" [(Q. 3:28).

Fifth, it evaluates and analyzes past nations and communities to present a clear understanding about life's journey and identifies the fundamental principles of truth-based and reality oriented critical thinking ${ }^{22}$ by discussing their scientific, technological, and intellectual achievements based upon a sound criteria of thinking critically. The Qur'an, which does not deny the importance of material development, argues in favor of one's spiritual existence.

And remember how He made you heirs to [the tribe of] Ad and settled you firmly on Earth, so that you [are able to] build for yourselves castles on its plains and carve out mountains [to serve you] as dwellings: remember, then, Allah's blessings and do not act wickedly on Earth by spreading corruption. (Q. 7:74)

Sixth, it points out that without identifying and applying the truth and reality of life and the world, all of their achievements could not guarantee a life of peace, happiness, prosperity, security, and quality. In fact, this failure engendered chaos, crisis, corruption, and destruction.

Finally, the Qur'an presents a criterion of thinking and critical thinking, the most important aspect of which is intimately related to the claim of the availability of the knowledge described above. First, it challenges humanity: "Among them are also the unlettered folk who do not know about the Books but cherish baseless wishes and merely follow their conjectures" (Q. 2:79); "Do you attribute to God something about which you have no knowledge?" (Q. 2:81) 23; and "But most people do not know the Truth, and have, therefore, turned away from it" (Q. 21:25).

It also rejects all philosophical and ideological claims of relativism, pragmatism, empiricism, rationalism, and scientism. ${ }^{24}$ In terms of the metaphysical domain, it accepts the need and necessity of true, authentic, and universal knowledge and that humanity has benefitted from it since its creation.

[O Muhammad,] We have revealed to you as We revealed to Noah and the Prophets after him, and We revealed to Abraham, Ishmael, Isaac, Jacob and the offspring of Jacob, and Jesus and Job, and Jonah, and Aaron and Solomon, and We gave to David Psalms. ... Those who denied this Truth and barred others from the way of Allah have indeed strayed far away. (Q. 4:163, 168) 
It also clarifies that all communities and nations have thought, studied, analyzed, and understood life and the world in terms of either conjecture and speculation or of true, authentic, and universal knowledge. It also proves that August Comte's (1798-1857) Law of the Three Stages of Human Development is just a theory, for it has not been tested and verified based upon sound criteria of critical and scientific thinking or supported by historical and empirical evidence. The Qur'an repeatedly argues that it contains the latter type of knowledge $^{25}$ - God's revelation throughout history, but in different forms and styles - and invites all people to verify and test its claims.

All post-Enlightenment intellectual, scholarly, scientific, and technological activities have been grounded upon conjecture and speculation. The Qur'an has this to say about these so-called philosophical, ethical, scientific, empirical, critical, and rational studies: "No one can inform you of the truth save the All-Aware" (Q. 35:14); "Say: "None in the heavens and on Earth has knowledge of the Unseen save God"" (Q. 27:65); "Is the knowledge of the Unseen with him so that he sees?" (Q. 53:35); and "Or is it that they have access to [the Truths in] the realm beyond sense-perception which they are writing down?" (Q. 52:41).

The Qur'an claims to present true, authentic, and universal knowledge. Therefore, it asserts that conjecture and speculation cannot provide the correct foundation for intellectual understanding and scientific confirmation of life and the world. ${ }^{26}$

\section{The Principles of Truth-Based and Reality Oriented Critical Thinking}

Before elaborating the principles of truth-based and reality oriented critical thinking, it seems appropriate to offer a realistic and meaningful definition of this concept. Here, it is necessary to understand two things: (1) critical thinking transcends those cognitive skills or strategies that may increase the possibility of solving some problems or issues and (2) that truth-based and reality oriented critical thinking may be defined as an intellectual activity that helps evaluate, analyze, conceptualize, and develop an accurate understanding of the issues of vision and mission of life and society. It vigorously applies rational arguments and historical and empirical evidence, as well as certain skills and techniques, to evaluate statements, policies, or programs; helps replace the existing notion of critical thinking; and explains the importance and significance of truth, reality, and all other things of this world. As detailed above, the dominant notion of critical thinking has been reduced to the level of mere skills and techniques 
and, as a result, has lost its true meaning, purpose, and characteristics: to help improve our process of thinking and conditions of life.

In the light of the above discussion, we can outline some fundamental principles of critical thinking by the following chart.

Chart 1. The Fundamental Principles of Critical Thinking

The need for ethical inquiry supported by historical and empirical evidence.

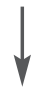

The existence of true, authentic, and universal knowledge (i.e., Islamic revealed knowledge) based on a rational, historical, and empirical approach.

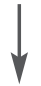

The acceptance of a true, authentic, and universal worldview.

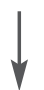

The acceptance of an ethical, empirical, spiritual, moral, universal, and people-oriented basis of life and the world, as well as of the rise and fall of civilization.

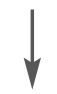

The acceptance of ethical, spiritual, and moral values received from the true, authentic, and universal knowledge combined with human resource development.

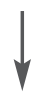

The acceptance of the need of knowledge, education, discipline, scientific and technological advancement, economic growth, political stability, political legitimacy, the proper management of resources both human and material, and the application of skills, techniques, and procedures.

One characteristic of this type of critical thinking is helping people overcome the internal logical inconsistencies in a given statement, idea, or policy by providing truthful and realistic criterion. As we cannot develop a strong foundation of thinking and critical thinking on our own, I argue that we need to replace conjecture and speculation with true, authentic, and universal knowledge, which always directs us, in a meaningful way, to the right conclusions. This type of knowledge creates truth-based and reality oriented understanding and explains life, which was created by God, and its vision and mission, which differ from those of the existing dominant materialistic view. ${ }^{27}$ 
The Qur'an challenges critical thinkers as well as knowledgeable and wise people. To establish this, it develops an ethical discourse and provides historical and empirical evidence for it: "Do they not ponder about the Qur'an? Had it been from any other than God, they would surely have found in it much inconsistency" (Q. 4:82). Hence, I claim that the truth and reality of life and the world have been made known to everybody. Those philosophers who based their pronouncements upon reason and sense perception alone failed to realize and recognize their own position and faculties. "He has the keys to the realm that lies beyond the reach of human perception; none knows them but He. And He knows what is on the land and in the sea" (Q. 6:59) ${ }^{28}$ Clearly, the truth and reality of life and the world is that it is spiritual and moral, as opposed to just materialistic. And so all aspects of life and society are spiritual and moral as well. If they are absent, we must subject life and society to an in-depth critical examination and evaluation.

The characteristics of truth-based and reality oriented critical thinking, in fact, differ from those of critical thinking, for the former are not limited to examining and questioning the assumed sound and relevant assumptions, presuppositions, or perceptions. In fact, the first type of critical thinking, which is presented in the Qur'an, helps humanity fulfills its life's purpose and and achieve its own wellbeing. The Qur' an reveals that everyone is subject to the laws of nature and to God's moral and social laws, ${ }^{29}$ which means that humanity can achieve peace, security, prosperity, happiness, and development via its total and voluntary submission to God.

Humanity's declaration of maturity, self-sufficiency and liberation from God's guidance is the result of ignorance, speculation, and conjecture - a fact that is also mentioned in the Qur'an. ${ }^{30}$ The failure of human faculties to solve society's complex problems is by itself empirical evidence. ${ }^{31}$ Thus, according to truth-based and reality oriented critical thinking, humanity needs to become aware of the implications of denying God's existence and not submitting to Him completely. If this type of critical thinking fails in this regard, it can no longer be considered "critical," meaning that it can no longer distinguish truth from falsehood, reality from unreality, right from what is wrong as well as the place of pluralism and plurality.

There are other points as well. First, this type of critical thinking rejects dogmatic, speculative, and conjectural methods and therefore distinguishes the materialistic approach to life from the spiritual and moral approach. Moreover, it goes beyond observable reality and discloses the unobservable reality of spiritual existence and the need to apply a universal set of morals approved by true, authentic, and universal knowledge. ${ }^{32}$ 
Second, it criticizes humanity's lower materialistic goals, highlights the high and noble goals of human welfare and development based upon a spiritual and moral foundation, and outlines the framework that guarantees the humanity's wellbeing. Modern society's institutions and people think and act in terms of material benefits only, which creates conflicts of interest, raises negative feelings (e.g., greed, corruption, and exploitation), promotes material competition, and reduces the sense of material cooperation and sacrifice. On the other hand, truth-based and reality oriented critical thinking states that one cannot attain true wellbeing based upon speculation and conjecture.

Third, it ascertains that from an ethical point of view, life is both spiritual and moral. The lack of such a foundation has made people so arrogant that they prefer to produce more weapons ${ }^{33}$ than food and to engage in evil and ignore virtue. Fourth, it highlights the unnecessary emphasis on amusement and entertainment, which seems to indicate the lack of a sense of life's spiritual reality. The set of morals sanctioned by God are no longer respected. ${ }^{34}$ This kind of critical thinking challenges modernity's entire worldview.

Fifth, it logically, rationally, and scientifically reveals the shallowness of modernity's materialistic and relativistic view of life in favor of the spiritual and moral view of life. For example, it criticizes those who talk about banning weapons of mass destruction only to produce and continue to sell them, ${ }^{35}$ those who produce commodities using unhealthy minerals, and the unending competition for so-called technological advancement. It therefore promotes the framework of 'amr bi al-ma' 'rüf wa nahi an al-munkar ${ }^{36}$ by diverting our focus from ethical and scientific skills in order to elaborate and then help us follow the straight path of development, ${ }^{37}$ prosperity, security, peace, and happiness.

\section{Conclusion}

Clearly, the current structure of critical thinking, based upon conjecture and speculation, needs to be replaced with truth-based and reality oriented critical thinking, which uses the criteria of true, authentic, and universal knowledge to distinguish truth from falsehood. Thus, the notions of the necessity of scientific and technological advancement, economic growth and development, political stability and globalization, as well as the development of information technology need to be analyzed and criticized. But such an undertaking is impossible due to the corruption, selfishness, and greed that now drive us and almost all societies. ${ }^{38}$ What is needed today are integrated, spirituality oriented, and moral 
human beings and societies that stand up against corruption, greed, exploitation, and injustice. This requires a complete overhauling of our existing notions of thinking and critical thinking.

I conclude that truth-based and reality oriented critical thinking will enlighten humanity about the problematic dimension of existing concepts of thinking as well as critical and scientific thinking Statistics on drugs use, the sale of weapons, and the rise in corruption and crime are sufficient empirical proofs to argue the need for rethinking in these areas, as well as in our educational institutions, curricula, teachers, and all others need a new orientation for their lives and professions. ${ }^{39}$ The truth-based and reality oriented critical thinking presented in this article has to demolish the sense of supremacy that pervades contemporary models, theories, concepts, methods, sciences, ideologies, and so many -isms. Quite a few thinkers have commented that humanity is currently on the brink of total destruction and suicide. ${ }^{40}$ Hence, the perception and role of modern science have become questionable. ${ }^{41}$ Truthbased and reality oriented critical thinking will play a constructive role in saving humanity from itself.

\section{Endnotes}

1. Authors discuss the skills and techniques of critical thinking, such as argument recognition, analysis, and evaluation. See, for example, Debra Jackson and Paul Newberry, Critical Thinking: A User's Manual (Boston: Wadsworth, Cengage Learning, 2012); Burton. F. Porter, The Voices of Reason: Fundamentals of Critical Thinking (Oxford: Oxford University Press, 2002); Lewis Vaughn, The Power of Critical Thinking (Oxford: Oxford University Press, 2005); Larry Wright, Critical Thinking: An Introduction to Analytical Reading and Reasoning (Oxford: Oxford University Press, 2001).

2. For a better understanding of the term scientific, see Muhammad Mumtaz Ali and Siddiq Ali Chishti, "The Contemporary Intellectual Crisis and Lack of Clear Perception of Science and Scientific Thinking," Revelation and Science 5 no. 2 (2015): 33-50.

3. On the issue of metaphysical framework, see Richard F. Kitchener (ed.), The Worldview of Contemporary Physics: Does it Need a New Metaphysics? (Albany: State University of New York Press, 1988).

4. The available literature on critical thinking shows that all authors discuss and focus on the techniques and skills of critical thinking. See, for example, Edward S. Inch et al., Critical Thinking and Communication: The Use of Reasoning in Argument, 4th ed. (London: Allyn and Bacon, 2002); W. Edgar Moore et al., Creative and Critical Thinking (Boston: Houghton Miffin Company, 1985); Gerard I. Nierenberg, The Art of Creative Thinking (New York: Simon \& Schuster, 1986). 
5. I have argued elsewhere that our basic need is to have truthful and realistic idea of life and the world, the negligence of which is tantamount to the absence of a scientific approach. See Ali and Chishti, "The Contemporary Intellectual Crisis."

6. Ibid.

7. We find no discussion of this subject in the available literature.

8. Muhammad Mumtaz Ali, "What is Ethical in Ethics: An Exploration into the Universal Foundational Principles of Ethics," Paper presented at the International Conference for American Academic Disciplines, Harvard University, Boston, organized by the International Journal of Arts and Sciences, Central Connecticut State University, May 28-30, 2010.

9. The Qur'anic verses about the power of our faculties do not support the rationalist and empiricist claim of the superiority of reason and sense perception. For example: "And certainly We have created for Hell many of the jinn and humanity. They have hearts with which they fail to understand, eyes with which they fail to see, and ears with which they fail to hear. They are like cattle - indeed, even more astray. Such are utterly heedless" (Q. 7:179) and "Do not be like those who say: 'We hear,' although they do not hearken. Indeed, the worst kind of beasts in Allah's sight are the people who are deaf and dumb and who do not understand" (Q. 8:21-22).

10. For an alternative framework of critical thinking see, Muhammad Mumtaz Ali, Islamic Critical Thinking (Kuala Lumpur: Pearson, Kuala Lumpur, 2011).

11. See Q. 10:66-67 and 53:28.

12. In the existing literature on critical thinking, subjects such as reliance on authority, black-and-white thinking frame of reference, and others have been considered obstacles to critical thinking. See, for example, Vincent E. Barry, Invitation to Critical Thinking (New York: Holt, Rinehart and Winston, 1984), 3-4.

13. See Q. 13, 53:23-24, 11:24, and 39:9.

14. Rationalism, empiricism, relativism, scientism, pragmatism, and other modern theories of knowledge have rejected the idea of true, authentic and universal knowledge.

15. Q. 15, 4:157, and 6:119.

16. Ali, "What is Ethical in Ethics"; Ali, "The Contemporary Intellectual Crisis."

17. Merrilee H. Salmon, Introduction to Logic and Critical Thinking, 6th ed. (Boston: Wadsworth, Cengage Learning, 2013); Gregory Bassham et al., Critical Thinking: A Student's Introduction, 5th ed. (New York: The McGraw Hill Companies, 2013); Alec Fisher, Critical Thinking: An Introduction, 2 d ed. (Cambridge: Cambridge University Press, 2011); Tracy Bowell and Gary Kemp, Critical Thinking: A Concise Guide, 3d ed. (New York: Routledge, 2010).

18. We find repetition. See, for example, Salmon, Introduction; Bassham et al., Critical Thinking; Fisher, Critical Thinking; and Bowell and Kemp, Critical Thinking.

19. Q. 31:21 and 2:171.

20. Q. 18:1-5 and 31:6. 
21. Q. 3:164-66, 11:1-2, and 16:64.

22. See, for details, chapters 2-5 of the Qur'an.

23. Q. 2:88, 121, and 146; 53:24-25 and 28-29.

24. William F. Lawhead, The Philosophical Journey: An Interactive Approach, 6th ed. (New York: Mc Graw Hill Education, 2011), 167-307.

25. God asks people who speak about the unseen aspects of life: "Do you have any clear authority for such claims? Bring your Book, if you are truthful" (Q. 37:15657). Also see Q. 7:52, 6:52, and 4:168.

26. Q. 4:157, 6:116 and 148 , and $16: 119$.

27. Q. 27:6, 40:1-2, and 39:1-2.

28. Q. 31:34 and 23:92.

29. See Q. 2:27, 3:62-63, and 16:88.

30. Several Qur'anic verses refer to failure of human faculties if they are not used properly, such as Q. 7:179, 22:46, and 6:25.

31. All governments and NGOs take the advice of experts but remain unable to solve problems.

32. The Qur'an provides a set of morals, the rejection of which causes chaos and crisis in life and society. See Q. 2:27, 83-86, 215, 177 and 7:142.

33. See the on-line reports of statistics on the production and sale of weapons.

34. Recently, President Barack and former Secretary of State Hillary Clinton accepted homosexuality and lesbianism. These are no longer considered sins or crimes in the modern world.

35. America and the European Union champion arms control, yet every year they sell the highest number of weapons.

36. Q. 3:104.

37. Q. 15:15-16;1:6; 2:16, 82, and 225 .

38. R. J. Baum, Doctors of Modernity: Darwin, Marx and Freud (Peru, IL: Sherwood Sugden, 1988).

39. For the needs of a new educational system and curriculum see, Harry R. Lewis, Excellence without A Soul (New York: BBS Public Affairs, 2006).

40. See especially the concluding remarks of Samuel P. Huntington, The Clah of Civilizations and the Remaking of World Order (New York: Simon and Schuster, 1996), 321.

41. For a different point of view on modern western education, see Muhammad Mumtaz Ali, The History and Philosophy of Islamization of Knowledge (Kuala Lumpur: IIUM Press, 2013) and Muhammad Mumtaz Ali, Issues in Islamization of Human Knowledge (Kuala Lumpur: IIUM Press, 2014). 